\title{
MÉTODO DOS ELEMENTOS FINITOS: NÚCLEOS METÁLICOS FUNDIDOS E PINOS EM FIBRA DE CARBONO
}

Alfonso SÁNCHEZ-AYALA; Ana Paula Gebert de Oliveira FRANCO; Nerildo Luiz ULBRICH; Osnara Maria Mongruel GOMES

Dentes tratados endodonticamente tornam-se fragilizados por perda de irrigação que anteriormente era promovida pela polpa e por perda estrutural. Retentores intra-radiculares passaram a ser utilizados com o objetivo de reter o material de reconstrução coronária. Núcleos metálicos fundidos são muito utilizados para essa finalidade. Posteriormente, surgiram pinos pré-fabricados reforçados por fibras. Esse estudo tem o objetivo de comparar o comportamento biomecânico de núcleos metálicos fundidos e pinos em fibras de carbono cimentados em um incisivo central superior por meio do Método dos Elementos Finitos. Foi realizada a construção dos modelos dos dentes no programa AutoCAD 2000 e tranferidos para o programa Ansys 7.0, onde foram atribuídas as características físicas dos materiais, feita uma malha de triângulos eqüiláteros e o carregamento $(100 \mathrm{~N})$. Os resultados demonstraram um melhor comportamento biomecânico para o pino em fibras de carbono por possuir um módulo de elasticidade semelhante ao da dentina. 